\title{
Transfer of conditioned suppression and conditioned acceleration from instrumental to consummatory baselines
}

\author{
HANK DAVIS and DONALD SHATTUCK \\ University of Guelph, Guelph, Ontario, Canada
}

\begin{abstract}
Following training on a variable-interval food reinforcement schedule, rats were exposed to Pavlovian procedures which produced reliable conditioned suppression and conditioned acceleration of the leverpressing (instrumental) baseline. When free food was simultaneously made available in the test cage, all subjects spent the majority of each session "freeloading," that is, eating food from a dish rather than leverpressing for it. When superimposed upon the freeloading baseline, the conditioned suppression and conditioned acceleration procedures affected the rate of pellet consumption identically in magnitude and direction to their previous effects on leverpressing. These results suggest a motivational mechanism for conditioned suppression and acceleration, rather than one which depends upon spurious punishment of specific response sequences.
\end{abstract}

It is now widely held that Pavlovian conditioning procedures can be used to increase or decrease the rate of positively reinforced operant baselines. For example, excitatory tone-shock pairings result in suppression of an operant response during presentations of the tone-CS (e.g., Davis, 1968; Estes \& Skinner, 1941). Conversely, baseline responding may be accelerated by inhibitory Pavlovian arrangements involving shock. This may be accomplished by using a negative contingency between tone and shock such that an if-tone-then-no-shock condition is in effect (Davis \& McIntire, 1969; Hammond, 1966; Rescorla, 1967). Conditioned acceleration may also be produced by a procedure that separates shocks by some minimum interval. Under this arrangement, known as an autocontingency, an if-shock-then-no-shock condition prevails and responding is typically accelerated immediately following the offset of each shock (Davis, Memmott, \& Hurwitz, 1975).

There is some question as to whether the conditioned suppression procedure yields its well-established effect on consummatory responses as it does on instrumental response baselines. For example, Jackson and Delprato (1974) reported that an aversive CS that suppressed leverpressing did not affect the rate of eating food pellets that were delivered freely. Similarly, Decosta and Ayres (1971) reported that conditioned suppression of leverpressing was considerably stronger

This research was supported in part by Grant A0673 to Hank Davis from the National Research Council of Canada. The authors thank Harry Hurwitz, Jim Mottin, and John Memmott for their critical comments and Pati Beaudoin for her technical assistance. Reprints may be obtained from Hank Davis, Department of Psychology, University of Guelph, Guelph, Ontario N1G 2W1, Canada. D. Shattuck is now at McMaster University. than conditioned suppression of a sucrose licking response in the same subjects. Regarding the effects of conditioned acceleration, there appears to be no evidence at all that compares the effects of this inhibitory procedure on instrumental and consummatory baselines.

The present experiment addresses both of these issues: If the effects of conditioned suppression and conditioned acceleration procedures are first demonstrated on a conventional leverpress response baseline, can these procedures then be superimposed upon a different behavioral baseline, in this case consummatory behavior, such that their effects will be comparable in magnitude and direction to those originally observed on the leverpress baseline? Such an outcome (e.g., transfer of conditioned suppression from one behavioral baseline to another) would suggest that one can discuss conditioned suppression in terms that are motivational, rather than stressing the spurious punishing effects of shock on the baseline response (cf. Gottwald, 1967; Millenson \& de Villiers, 1972).

\section{METHOD}

\section{Subjects}

Nine experimentally naive male Long-Evans rats, about 150 days old, were reduced to approximately $80 \%$ of their free-feeding weights. These subjects were housed in individual cages under a 12-h light-dark cycle, with continuous access to water. Deprivation weights were maintained by the provision of supplementary food $1 \mathrm{~h}$ after each experimental session.

\section{Apparatus}

The subjects were tested in operant test chambers (Campden Instrument Co.), each located in a sound-attenuated box. Each chamber measured $24.5 \times 23 \times 20.5 \mathrm{~cm}$. A food hopper was located midway between two retractable bars situated on either side of 
the front panel. Responses were counted using the left lever, which was extended into the chamber during experimental sessions. Forty-five milligram Noyes pellets served as reinforcers. The floor of each chamber consisted of 16 stainless steel grids, $.9 \mathrm{~cm}$ in diameter and located $.9 \mathrm{~cm}$ apart. A constant-current shock generator (Campden Instrument Co.) was used to deliver 1-sec .6-mA scrambled shock. The CSs were 1-min 90 -dB (ref: .0002 dynes $/ \mathrm{cm}^{2}$ ) tones, with a frequency of $2,950 \mathrm{~Hz} \pm 5 \%$, provided by Mallory Sonalerts located on the roof of each chamber. Extraneous sounds were masked by white noise from a speaker in the ceiling of each room and by the circulation fans in each chamber.

\section{Procedure}

The subjects were randomly divided into one of three groups $(\mathrm{N}=3)$. The conditions of training and testing are summarized in Table 1 and described below.

\section{Experimental Group}

Phase I. The subjects were initially trained to leverpress for food reinforcement on a continuous reinforcement schedule. They were then exposed to 45 -min sessions on variable-interval (VI) schedules, the interval being gradually increased until a stable rate was obtained with a VI $30-\mathrm{sec}$ schedule (range $10-86 \mathrm{sec}$ ). VI training was continued for an average of 20 sessions.

Phase II. When baseline training was complete, the response levers were retracted and "off-line" CS-US experience was carried out for 14 sessions. During each 45-min session, four tones and six shocks occurred under the following procedure: Shocks were separated by a minimum 3-min interval, thus providing a shock/ no-shock autocontingency. Although a somewhat unconventional way to establish inhibitory control, the autocontingency procedure is in common use in our laboratory and yields reliable conditioned acceleration effects. In addition, four of the six shocks were preceded by $1-$ min tone $\mathrm{CS}$, thus establishing a positive traditional contingency (Rescorla, 1967) between tone and shock. The sequence of signaled and unsignaled shock trials was randomized between sessions. The four-CS/six-US procedure has proven effective in simultaneously establishing excitatory (suppressive) control by the $\mathrm{CS}$ and inhibitory (accelerative) control by the autocontingency (Davis \& Shattuck, 1978).

Phase III. This phase, which lasted 30 sessions, consisted of reintroducing the response lever and VI 30-sec reinforcement schedule while maintaining the CS-US and autocontingency experience begun in Phase II.

Phase IV. During Phase IV, a small ceramic dish (diameter $60 \mathrm{~mm}$, depth $20 \mathrm{~mm}$ ) containing $45-\mathrm{mg}$ Noyes pellets was placed on the rear floor of the chamber. Following an initial 10-min period with the food dish in Session 1, the response lever and VI schedule were reintroduced into the chamber. In order to determine the effects of the tone-shock and autocontingencies on the concurrent instrumental-consummatory baseline, performance was probed by three CS-US trials during each session. US occurrences were separated by a minimum 3-min interval. Five sessions were conducted, and performance was videotaped during each session. A minimum of two observers scored each tape by counting the number of pellets eaten. Interobserver reliability coefficients of .9 or better were obtained.

\section{Control Groups}

Two control groups were run in order to explore the possibility that suppression might be due to unconditioned effects of the $\mathrm{CS}$, or that postshock acceleration might result from shock-elicited aggression, "postsuppression rebound," or other nonassociative factors. Prior to testing in Phase IV, subjects in Control Group I received no experience with tone or shock. Thus, any suppressive or accelerative effects observed on free-feeding in Phase IV depended entirely upon nonassociative or unconditioned effects of the CS or US. Behavioral observations were terminated after a single session in order to avoid the development of CS-US or autocontingency control which might occur during extended testing. Control Group II was exposed to experience identical to that of the experimental group, with the exception that no autocontingency was programmed during Phases II-IV; that is, there was no restriction placed upon the intershock distribution, thus destroying the inhibitory shock/no-shock relation.

\section{RESULTS}

The results of the conditioned suppression and autocontingency procedures are summarized in Table 2 . The results are expressed as $\mathrm{A} /(\mathrm{A}+\mathrm{B})$ ratio values, where $A$ represents either the mean response rate during the 1-min CS (suppression) or during the 1-min period immediately following shock US (acceleration). $B$ represents the mean response rate derived from all non-CS and non-post-US minutes of the session. Ratio values may range from 0.00 (total suppression), through .5 (no change in baseline) to 1.00 (maximal conditioned acceleration).

Prior to the introduction of free food, all experimental subjects showed the effect of both the conditioned suppression and autocontingency procedures. During the final five sessions in Phase III, subjects leverpressed steadily until the CS occurred, at which point responding was suppressed. Immediately following delivery of shock, the rate of responding in all three animals was accelerated above the baseline value (see Table 2).

It was expected that following the introduction of free food into the chamber in Phase IV, the subjects

Table 1

Summary of Experimental and Control Group Treatment Conditions

\begin{tabular}{|c|c|c|c|}
\hline Phase & Experimental Group & Control Group 1 & Control Group 2 \\
\hline $\mathbf{I}$ & $\begin{array}{l}\text { Leverpress training on VI } 30-\sec \\
\text { schedule. }\end{array}$ & & $\begin{array}{l}\text { Leverpress training on VI } 30 \text {-sec } \\
\text { schedule. }\end{array}$ \\
\hline II & $\begin{array}{l}\text { "Off-line" exposure to CS-US } \\
\text { (tone-shock) contingency and } \\
\text { US-no US autocontingency. }\end{array}$ & & $\begin{array}{l}\text { "Off-line" exposure to CS-US } \\
\text { (tone-shock) contingency. No } \\
\text { autocontingency experience. }\end{array}$ \\
\hline III & $\begin{array}{l}\text { Exposure to CS-US and auto- } \\
\text { contingencies while responding } \\
\text { on VI } 30-\mathrm{sec} \text { schedule. }\end{array}$ & & $\begin{array}{l}\text { Exposure to CS-US contingency } \\
\text { while responding on VI } 30-\mathrm{sec} \\
\text { schedule. }\end{array}$ \\
\hline IV & $\begin{array}{l}\text { Introduction of food dish into } \\
\text { test chamber. Free-feeding } \\
\text { baseline probed with CS-US and } \\
\text { autocontingencies. }\end{array}$ & $\begin{array}{l}\text { Single session exposure to CS-US } \\
\text { trials during free-feeding baseline. }\end{array}$ & $\begin{array}{l}\text { Introduction of food dish into } \\
\text { test chamber. Free-feeding } \\
\text { baseline probed with CS-US } \\
\text { contingency. }\end{array}$ \\
\hline
\end{tabular}


Table 2

Effects of CS and Post-US Minutes on Leverpressing and Free-Feeding Baselines

\begin{tabular}{|c|c|c|c|c|c|c|}
\hline & \multicolumn{3}{|c|}{ Phase III: Leverpressing Baseline } & \multicolumn{3}{|c|}{ Phase IV: Free-Feeding Baseline } \\
\hline & $\begin{array}{c}\text { CS } \\
\text { Ratio }\end{array}$ & $\begin{array}{l}\text { Post-US } \\
\text { Ratio }\end{array}$ & $\begin{array}{c}\text { Baseline } \\
\text { Responses/Minute }\end{array}$ & $\begin{array}{l}\text { CS } \\
\text { Ratio }\end{array}$ & $\begin{array}{l}\text { Post-US } \\
\text { Ratio }\end{array}$ & $\begin{array}{l}\text { Baseline Pellets } \\
\text { Consumed/Minute }\end{array}$ \\
\hline \multicolumn{7}{|c|}{ Experimental Group } \\
\hline S1 & .00 & .82 & 16.4 & .00 & .75 & 5.3 \\
\hline S2 & .07 & .76 & 20.5 & .06 & .77 & 3.4 \\
\hline S3 & .02 & .81 & 15.7 & .01 & .82 & 4.6 \\
\hline \multicolumn{7}{|c|}{ Control Group $1^{*}$} \\
\hline $\mathrm{Cl}$ & & & & .43 & .39 & 4.6 \\
\hline $\mathrm{C} 2$ & & & & .48 & .41 & 4.3 \\
\hline $\mathrm{C} 3$ & & & & .41 & .36 & 5.0 \\
\hline \multicolumn{7}{|c|}{ Control Group 2} \\
\hline $\mathrm{C} 4$ & .02 & .46 & 17.8 & .00 & .43 & 5.4 \\
\hline $\mathrm{C} 5$ & .05 & .54 & 25.3 & .06 & .49 & 4.2 \\
\hline C6 & .00 & .49 & 19.6 & .04 & .44 & 3.8 \\
\hline
\end{tabular}

Note-Results are expressed in terms of $A /(A+B)$ ratios.

*Data are reported for Trials 2 and 3 of single test session.

would alternate between leverpressing and free feeding, thus allowing concurrent measurement of the effects of the two contingencies on instrumental and consummatory baselines. However, no subject showed such alternation between food sources; all subjects spent virtually the entire session at the free food dish. Of necessity, it was decided to probe the "freeloading" baseline with conditioned suppression and autocontingency procedures as planned, and to employ each subject's Phase III leverpressing data in the comparison between instrumental and consummatory baselines.

The effects of the CS-US and autocontingencies on the free-feeding baselines were virtually identical in magnitude and direction to those observed on leverpressing during Phase III. Because no consistent differences appeared across Phase IV, the data are averaged for all five test sessions. Suppression ratios computed on pellet acquisition were virtually identical to those recorded for the leverpressing baseline (see Table 2). All three subjects consumed pellets at a stable rate throughout the session. When the CS occurred, subjects typically "froze in their tracks," remaining positioned at the edge of the free-food dish. On those occasions when a pellet had been obtained but not swallowed prior to CS onset, chewing either stopped altogether or proceeded in what observers described as "slow motion." On rare instances in which a subject did retrieve a pellet during the CS, the actions were also performed in slow motion. On such occasions, pellet acquisition, which was normally accomplished with a darting movement taking less than $1 \mathrm{sec}$, typically occupied as much as $10 \mathrm{sec}$ of the CS.

The accelerative effects of the autocontingency on freeloading were quite dramatic. Like leverpressing, pellet consumption was markedly increased in the minute immediately following shock offset. Accelera- tion ratio values for this period are given in Table 2 . On those trials when shock occurrence threw the subject away from his station at the food dish, observers noted that the subject "lunged" or "flew" across the cage to resume eating.

Subjects in Control Group I had had no prior experience with the CS or US. The unconditioned effects of these two stimuli were observed during a single free-feeding session. Although the CS was initially disruptive, the effect appeared to be based upon a competing orienting response and decreased in magnitude over the three test trials. Virtually no suppression of eating was apparent for any subject by Trial 3.

Similarly, no subject increased his rate of freepellet consumption in the minute following shock. In fact, the unconditioned effects of US offset were, if anything, suppressive rather than accelerative. Such suppression was observed both in the periods immediately following shock and, to some extent, on the overall rate of eating throughout the session.

Data from Control Group II also bear on the question of whether accelerated responding, either during the leverpress or free-feeding baseline, resulted from an associative process. Subjects in this group were exposed to a conventional conditioned suppression procedure in Phases III and IV without the addition of a shock/no-shock autocontingency. Although all three subjects showed the suppressive effects of the CS on both leverpressing and free feeding, there was no indication of accelerated responding following shock on either of the baselines.

\section{DISCUSSION}

The degree of conditioned suppression and conditioned acceleration recorded for leverpressing behavior was virtually identical in magnitude and direc- 
tion to the suppression and acceleration recorded upon a baseline of free feeding. Moreover, the results of Control Groups I and II suggest that both suppression and acceleration of these two baselines were associative effects of exposure to the Pavlovian procedures.

The transfer of conditioned suppression from instrumental to consummatory baselines may bear upon how this procedure produces its effects. Blackman (1977) distinguishes between what he terms motivational explanations for conditioned suppression and the punishment hypothesis. The motivational view, which is perhaps most commonly used to explain conditioned suppression, accounts for changes in the rate of baseline responding in terms of a corresponding change in the motivational state of the subject. This state may be viewed in specific terms, such as "anxiety" (e.g., Estes \& Skinner, 1941; Ray, 1964), or couched in far more general terms, such as "conditioned emotional response" (e.g., Kamin \& Schaub, 1963 ) or "general emotional state" (Azrin \& Hake, 1969). In either case, it follows that baseline responding is merely a reflection of the motivational state that is produced by the CS. Thus, a shift in the choice of baseline response should have little or no bearing on the effects produced by a particular CS. This position is entirely consonant with the present finding that different response baselines were affected similarly in magnitude and direction under both the conditioned suppression and conditioned acceleration procedures.

In contrast, the present results do not support the punishment hypothesis. This position, elaborated by Lyon (1968), holds that delivery of shock may occasionally follow the baseline response, thereby producing a spurious punishment effect and reducing the rate of baseline responding. It is arguable that such associations between operant responding and shock USs are virtually inevitable at some stage of training. In fact, there are data to suggest that punishment artifacts may account for conditioned suppression. For example, Goitwald (1967) demonstrated that the degree of conditioned suppression on a particular trial was directly related to the proximity between shock and responding on the previous trial.

Nevertheless, the present data fail to support the punishment view. Crucial to this conclusion is the fact that the consummatory response, which was as readily suppressed as leverpressing, involved a different array of motor behaviors. Presumably, punishment effects would be confined to particular response sequences and would not show immediate transfer from one response class to the other. Moreover, the comparable transfer of conditioned acceleration suggests that the generality of this analysis may be extended from excitatory to inhibitory conditioning.

Although quite unexpected, it is worth noting that subjects failed to show either "contrafreeloading" or consistent alternation between leverpressing and free feeding. These results are quite unusual and in contrast to the findings typically reported under freeloading procedures (cf. Jackson, 1976; Neuringer, 1969). A number of procedural factors might underlie these conflicting results although none appears more obvious than the present use of shock within the test situation. It does not appear that freeloading experiments have previously been performed in situations which involve the concurrent use of an aversive control procedure (see review by Osborne, 1977). If this is, indeed, the basis for the conflicting results, then its theoretical implications are considerable. The presence of aversive stimuli, both conditioned and unconditioned, increased the likelihood of consummatory behavior over instumental responding. Why did subjects eat freely under these conditions rather than work for their food, as they tend to do in appetitive situations? It may be that the "work ethic," that laudable trait previously attributed to rats, may be confined to relatively unthreatening circumstances. The reason for this bias may be related to Bolles' (1970) discussion of species-specific defense reactions (SSDRs). In short, the presence of aversion increases the likelihood of more "primitive" behavioral classes; SSDRs are foremost among them, but consummatory behaviors are also primitive and may therefore become more probable than instrumental responses.

In summary, the present results support a relatively simple view of conditioned suppression and conditioned acceleration: a motivational state is conditioned and has direct impact on overt behavioral baselines, whether they be classified as instrumental or consummatory.

\section{REFERENCE NOTE}

1. Davis, H., \& Shattuck, D. Autocontingencies: Effects of unsignaled shock during a progressively degraded conditioned suppression procedure. Paper read at the 19th Annual Meeting of the Psychonomic Society, San Antonio, Texas, 1978.

\section{REFERENCES}

Azrin, N. H., \& Hake, D. F. Positive conditioned suppression: Conditioned suppression using positive reinforcers as the unconditioned stimuli. Journal of the Experimental Analysis of Behavior, 1969, 12, 167-173.

Blackman, D. Conditioned suppression and the effects of classical conditioning on operant behavior. In W. K. Honig \& J. E. R. Staddon (Eds.), Handbook of operant behavior. Englewood Cliffs, N.J: Prentice-Hall, 1977.

Bolles, R. C. Species-specific defense reactions and avoidance learning. Psychological Review, 1970, 77, 32-48.

Davis, H. Conditioned suppression: A survey of the literature. Psychonomic Monograph Supplements, 1968, 2(Whole No. 30), 283-291.

Davis, H., \& McIntrae, R. Conditioned suppression under positive, negative, and no contingency between conditioned and unconditioned stimuli. Journal of the Experimental Analysis of Behavior, 1969, 12, 633-640.

Davis, H., Memmott, J., \& Hurwitz, H. M. B. Autocontin- 
gencies: A model for subtle behavioral control. Journal of Experimental Psychology: General, 1975, 104, 169-188.

DeCosta, M. J., \& Ayres, J. J. B. Suppression of operant vs. consummatory behavior. Journal of the Experimental Analysis of Behavior, 1971, 16, 133-142.

Estes, W. K., \& Skinner, B. F. Some quantitative properties of anxiety. Journal of Experimental Psychology, 1941, 29, 390-400.

GotTwald, P. The role of punishment in the development conditioned suppression. Physiology \& Behavior, 1967, 2, 283-286.

H A m MOND, L. Increased responding to CS - in differential CER. Psychonomic Science, 1966, 5, 337-338.

JaCkson, D. E. Within-session observation of rats leverpressing in the presence of free food. Bulletin of the Psychonomic Society, 1976, 8, 292-294.

Jackson, D. E., \& Delprato, D. J. Aversive CSs suppress leverpressing for food but not the eating of free food. Learning and Motivation, 1974, 5, 448-458.

Kamin, L., \& Schaub, R. E. Effects of conditioned stimulus intensity on the conditioned emotional response. Journal of Comparative \& Physiological Psychology, 1963, 56, 502-507. LYON, D. O. Conditioned suppression: Operant variables and aversive control. Psychological Record, 1968, 18, 317-338.

Millenson, J. R., \& DE Villie rs, P. A. Motivational properties of conditioned anxiety. In R. M. Gilbert \& J. R. Millenson (Eds.), Reinforcement: Behavioral analyses. New York: Academic Press, 1972.

Neuringer, A.J. Animals respond for food in the presence of free food. Science, 1969, 166, 399-401.

Osbornf. S. R. The free food (contrafreeloading) phenomenon: A review and analysis. Animal Learning \& Behavior, 1977, 5, 221-235.

$\mathrm{R}_{\mathrm{A}}$, O. S. Tranquilizing effects as a function of experimental anxiety procedures. Archives Internationales de Pharmacodynamic et de Thérapie, 1964, 153, 49-68.

REsCorla, R. A. Pavlovian conditioning and its proper control procedures. Psychological Review, 1967, 74, 71-80.

(Received for publication April 24, 1979; revision accepted October $9,1979$. 